\title{
Gêneros de macroliquens do campus da Universidade Federal de São Carlos - UFSCar, Município de São Carlos, Estado de São Paulo, Brasil
}

\author{
Gisele Gandra Batista ${ }^{1}$ e Michel Navarro Benatti ${ }^{1,2}$
}

Recebido: 9.06.2010; aceito: 2.06.2011

\begin{abstract}
Macrolichen genera from the campus of Universidade Federal de São Carlos - UFSCar, São Carlos city, São Paulo State, Brazil). This work consists on a survey of the of the lichen genera with foliose, fruticose and dimorphic thalli of the Universidade Federal de São Carlos campus, São Carlos municipality, São Paulo State countryside, Brazil. Samples were collected in urban, cerrados (tropical savanna) and riparian wood areas, noting the occurrence of 21 genera. Here we present commented descriptions and an identification key for the genera found.
\end{abstract}

Key words: cerrados, macrolichens, riparian wood, UFSCar campus

RESUMO - (Gêneros de macroliquens do campus da Universidade Federal de São Carlos - UFSCar, Município de São Carlos, Estado de São Paulo, Brasil). O trabalho consistiu no levantamento dos gêneros de fungos liquenizados de talos foliosos, fruticosos e dimórficos que ocorrem no campus da Universidade Federal de São Carlos, Município de São Carlos, interior do Estado de São Paulo, Brasil. Foram coletadas amostras nas áreas urbanizadas, de cerrado, e de mata de galeria, constatandose a ocorrência de 21 gêneros. São apresentadas descrições comentadas e uma chave de identificação para os gêneros encontrados.

Palavras-chave: campus da UFSCar, cerrado, macroliquens, mata de galeria

\section{Introdução}

No Estado de São Paulo existem biomas onde a micobiota liquenizada ainda não foi levantada ou possui poucos estudos, estes até o momento contemplando em sua maioria apenas alguns gêneros ou famílias, pois faltam recursos humanos e financeiros, o que dificulta a realização de estudos mais abrangentes (Marcelli 1996). Entretanto, o campus da Universidade Federal de São Carlos - UFSCar - localizado no Município de São Carlos, interior de São Paulo, encerra em suas dependências centenas de hectares de vegetações preservadas, onde podem ser vistos muitos liquens.

A diversidade de habitats no campus da UFSCar permitiu estudar a micobiota liquenizada em áreas de cerrado, mata de galeria e áreas urbanizadas, de modo a contribuir para o acréscimo do conhecimento da flora deste campus. Entretanto, os dois primeiros habitats sofrem ameaças constantes com a expansão urbana do campus e com incêndios, sendo as áreas de cerrado as mais vulneráveis.

Este é o primeiro estudo florístico com liquens nesta área, sendo também o primeiro estudo deste tipo em um campus brasileiro. São poucos os trabalhos conhecidos para as regiões centro-oeste e noroeste do Estado de São Paulo, e o único estudo conhecido para a região abrangeu espécies de apenas uma família (Parmeliaceae), em trechos de cerrados em Itirapina, Corumbataí e São José do Rio Preto (Jungbluth 2006), onde foram encontradas mais de 90 espécies pertencentes a 12 gêneros.

O objetivo desta pesquisa foi estudar quais os gêneros de liquens foliosos, fruticosos e dimórficos que ocorrem nas dependências do campus da Universidade Federal de São Carlos. São apresentadas uma chave de identificação, descrições, comentários e ilustrações de espécimes dos gêneros encontrados.

1. Instituto de Botânica, Caixa Postal 68041, 04045-972 São Paulo, SP, Brasil

2. Autor para correspondência: michel_benatti@yahoo.com.br 


\section{Material e métodos}

A área de estudo desta pesquisa, o campus da Universidade Federal de São Carlos, localiza-se no Município de São Carlos, interior do Estado de São Paulo, de $21^{\circ} 58^{\prime}-22^{\circ} 00^{\prime} \mathrm{S}$ e $47^{\circ} 51^{\prime}-47^{\circ} 52^{\prime} \mathrm{W}$, distante $230 \mathrm{~km}$ da capital. A altitude varia entre 815 e $895 \mathrm{~m}$, e a área total do campus é de 643,08 ha. A temperatura média anual é de $19,6^{\circ} \mathrm{C}$ e a precipitação média anual é de $1.495,1 \mathrm{~mm}$, com o mínimo pluviométrico ocorrendo geralmente entre os meses de abril e setembro (Paese 1997). A rede hidrográfica do campus é composta de três represas, Mayaca, Fazzari e Monjolinho, e também de parte da represa do clube da ABASC (Associação Beneficente dos Alfaiates de São Carlos). Atravessam o campus os córregos do Fazzari, do Monjolinho e do Espraiado (Paese 1997).

O campus possui uma área urbanizada de 114,48 ha destinada às atividades acadêmicas e administrativas, onde se encontram edificações, ruas, estacionamentos e calçadas pavimentados, alguns bosques, gramados e jardins (Paese 1997). A área não urbanizada do campus é de 528,59 ha (Paese 1997), onde se encontra a vegetação de cerrado, com fisionomia predominante de cerrado sensu stricto (Coutinho 1978). Trata-se de uma área de vegetação secundária regenerada, onde se encontram também matas de galeria junto a alguns córregos, com vegetação caracterizada por diferentes estratos, variando de um herbáceo-arbustivo até um estrato arbóreo heterogêneo (Paese 1997).

Foram coletadas 241 amostras de fungos liquenizados foliosos, fruticosos e dimórficos em diversos pontos do campus da UFSCar, durante setembro de 2006, abrangendo as áreas urbanizadas, de cerrado e de mata de galeria. Os talos foram coletados sobre todos os substratos em que puderam ser encontrados, removidos com auxilio de faca comum e martelo. Eventualmente, para talos corticícolas muito aderidos, removeu-se cuidadosamente o líquen juntamente com um pequeno pedaço do substrato, para minimizar danos as cascas das árvores. Os espécimes coletados foram preferencialmente talos inteiros e sadios, mantidos os mais intactos possíveis.

As coletas foram guardadas individualmente em sacos de papel pardo, nos quais foram anotados dados sobre a amostra, o substrato e o local. As amostras foram inicialmente secas ao ar livre, e posteriormente colocadas em um freezer a temperaturas de aproximadamente $-20{ }^{\circ} \mathrm{C}$ para eliminar a presença de pequenos artrópodes, seus ovos e larvas do material, logo depois iniciando-se a triagem e identificação.

A identificação do material foi feita com análises morfológicas e anatômicas das estruturas somáticas e de reprodução direta ou indireta dos talos com o uso de estereomicroscópio. Os ascomas e seus ascósporos foram estudados sobre microscópio óptico através de cortes finos feitos à mão livre. Análises químicas por testes de coloração tipos K (hidróxido de potássio), C (hipoclorito de sódio) e KC (combinação dos dois reagentes) foram efetuadas, a fim de averiguar quais as possíveis substâncias de importância taxonômica encontradas nos espécimes coletados.

A identificação dos gêneros foi feita conforme a metodologia tradicional em liquenologia taxonômica (Fink 1905, Hale 1979, Galloway 1985, 2007), mediante o uso de chaves de identificação e bibliografia especializada (Aptroot 1987, Swinscow \& Krog 1988, Fleig \& Medeiros Filho 1990, Purvis 2000, Brodo et al. 2001, Benatti 2005, Canêz 2005, Spielmann 2005, Jungbluth 2006, Benatti \& Marcelli 2007, Spielmann \& Marcelli 2008 e Canêz \& Marcelli 2009). O material foi depositado no Herbário da Universidade Federal de São Carlos (HUFSCar).

\section{Resultados e Discussão}

Os 241 espécimes de macroliquens estudados pertencem a 21 gêneros de fungos liquenizados, sendo 17 gêneros foliosos, três gêneros fruticosos e um gênero dimórfico. A classificação apresentada neste trabalho segue Kirk et al. (2008). Os gêneros encontrados pertencem a nove famílias, das Ordens Lecanorales, Peltigerales e Teloschistales, da Classe Ascomycetes, Filo Ascomycota.

Nota-se nos locais o predomínio de espécimes da família Parmeliaceae, com boa representatividade também dos da família Physciaceae. Os gêneros estudados são conhecidos para outras áreas do Estado de São Paulo, sendo que não foram encontrados alguns gêneros esperados para a área de estudo, mencionados na literatura consultada.

Pela variedade de características vistas nos talos encontrados, o local apresenta uma interessante diversidade de espécies ainda a ser investigada, apesar da vegetação não ser muito antiga e sofrer com freqüentes impactos por incêndios, que ocorrem principalmente nas áreas de cerrado.

São apresentadas a seguir uma chave de identificação e as descrições dos gêneros encontrados. 
Chave para os gêneros de fungos liquenizados foliosos, fruticosos e dimórficos do campus da UFSCar

1. Talo dimórfico ou fruticoso

2. Talo dimórfico, talo primário esquamuloso (as vezes ausentes em talos maduros) e talo secundário fruticoso, ereto (podécio); medula central oca; apotécios lecideinos

2. Talo fruticoso, de forma arbustiva, ereta ou pendulosa; medula com hifas frouxas (aracnóide) ou mais compactas; apotécios lecanorinos

3. Talo com cordão axial central condróide; ascósporos simples Usnea

3. Talo sem cordão axial; ascósporos transversalmente septados

4. Ramificações achatadas; córtex K- ou K+ amarelo; ascósporos biloculares Ramalina

4. Ramificações cilíndricas; córtex $\mathrm{K}+$ púrpura; ascósporos polariloculares Teloschistes

1. Talo folioso

5. Talo homômero (sem distinção entre medula e camada de fotobionte), de aspecto gelatinoso quando úmido; ascósporos muriformes; fotobionte cianobactéria do gênero Nostoc.

5. Talo heterômero (camada de fotobionte e medula distintos), de aspecto não gelatinoso seco ou úmido; ascósporos simples ou transversalmente septados, fotobionte clorófita ou cianobactéria

6. Talo escuro, cinza, verde ou marrom; lado de baixo tomentoso

7. Talo cinza chumbo a cinza azulado (lobos com linhas circulares concêntricas e estrias radiais), sem poros no córtex inferior, apotécio lecideino; fotobionte sempre cianobactéria Coccocarpia

7. Talo esverdeado a amarronzado; córtex inferior com cifelas ou pseudocifelas (poros); apotécio lecanorino, ascósporos transversalmente sepados; fotobionte cianobactéria ou clorófita

8. Córtex inferior com cifelas (poros corticados) Sticta

8. Córtex inferior com pseudocifelas (poros ecorticados) Pseudocyphellaria

6. Talo claro, acinzentado, esverdeado, ou amarelado; lado de baixo rizinado ou glabro

9. Talo amarelo vivo a amarelo; lacínias estreitas ( $\leq 1 \mathrm{~mm}$ larg.); ascos com dezenas de ascósporos Candelaria

9. Talo branco, cinza ou esverdeado; lobos ou lacínias $\geq 3 \mathrm{~mm}$ larg.; ascos contendo 8 ascósporos

10. Talo branco, cinza claro ou cinza esverdeado claro, lado de baixo com córtex inferior creme, marrom acinzentado ou ecorticado; apotécios com discos negros; ascósporos marrons, biloculares

11. Talo adnato muito adpresso ao substrato; córtex inferior negro sem rizinas; lacínias confluentes, em geral fundidas lateralmente

Dirinaria

11. Talo adnato pouco adpresso ao substrato ou solto; lado de baixo ecorticado ou com córtex inferior rizinado; lacínias ou lobos não confluentes, não fundidos lateralmente

12. Talo com margens ou córtex superior ciliados; córtex superior prosoplectenquimático (hifas arranjadas longitudinalmente), com delicadas estrias radiais; lado de baixo com ou sem córtex Heterodermia

12. Talo sempre sem cílios; córtex superior paraplectenquimático (hifas emaranhadas compactadas), de aspecto homogêneo sem estrias; lado de baixo sempre corticado

13. Apotécio quando desenvolvido lecideíno (sem excípulo talino); córtex inferior negro; córtex superior K- ; hipotécio marrom escuro; epitécio $\mathrm{K}+$ púrpura Pyxine

13. Apotécio sempre lecanorino (com excípulo talino); córtex inferior creme ou marrom claro; córtex superior $\mathrm{K}+$ amarelo; hipotécio claro; epitécio K- 
10. Talo verde acinzentado ou verde amarelado; córtex inferior negro a marrom acastanhado; apotécios com discos marrons, ascósporos simples e incolores

14. Pseudocifelas presentes no córtex superior

14. Pseudocifelas ausentes

15. Cílios marginais presentes

16. Cílios com base inflada (bulbados)

Bulbothrix

16. Cílios com base não inflada (não bulbados)

17. Cílios distribuídos por toda a margem, de freqüentes a abundantes

18. Lobos estreitos, de ápices truncados, geralmente 1-2 mm larg. Parmelinopsis

18. Lobos largos, de ápices arredondados, geralmente 5-30 mm larg.

19. Córtex superior sem máculas, ou com máculas lineares ou puntiformes escassas; córtex inferior com margens nuas.

Parmotrema

19. Córtex superior com máculas efiguradas puntiformes ou reticulares; córtex inferior com margens rizinadas

20. Córtex superior com máculas reticulares, frequentemente originando quebras e ficando rimosos; rizinas monomórficas Parmotrema (ex Rimelia)

20. Córtex superior com máculas puntiformes, com raras quebras; rizinas dimórficas, longas e grossas misturadas a pequenas e finas ...... Parmotrema (ex Canomaculina)

17. Cílios restritos as axilas dos lobos, de poucos a escassos

21. Medula branca, com ácido salazínico $(\mathrm{K}+$ amarelo $\rightarrow$ vermelho $)$ Parmelinella

21. Medula amarela, com ácido secalônico ( $\mathrm{K}+$ amarelo forte)

Myelochroa

15. Cílios marginais ausentes

22. Lobos largos, > $5 \mathrm{~mm}$; córtex inferior com margens nuas

Parmotrema

22. Lobos estreitos, $\leq 5 \mathrm{~mm}$; córtex inferior com rizinas até as margens

23. Rizinas dicotomicamente ramificadas Hypotrachyna

23. Rizinas geralmente simples em parte um pouco irregularmente ramificadas Canoparmelia

As descrições dos gêneros são apresentadas a seguir em ordem alfabética, para facilidade de consulta, baseadas no material encontrado. A principal bibliografia consultada foi: Galloway $(1985,2007)$, Aptroot (1987), Hale (1987), Swinscow \& Krog (1988), Fleig \& Medeiros Filho (1990), Ribeiro (1998), Ahti (2000), Brodo et al. (2001), Kirk et al. (2008), Benatti (2005), Canêz (2005), Spielmann (2005), Jungbluth (2006), Canêz \& Marcelli (2009) e Spielman \& Marcelli (2009).

Bulbothrix Hale (1974) [Lecanorales, Parmeliaceae] Figura 1

Talos foliosos, corticícolas, adnatos a muito adnatos e adpressos; córtex superior cinza esverdeado claro a cinza pardacento, máculas ausentes ou puntiformes, medula branca, córtex inferior negro a marrom, com margens marrons claras; cílios simples a ramificados, marginais ou axilares, de base bulbada, enegrecidos; rizinas simples a ramificadas, marrons a negras; apotécios com excípulo talino, adnatos, disco marrom, himênio com paráfises simples, ascos clavados, contendo 8 ascósporos por asco; ascósporos simples, elipsóides, hialinos; fotobionte: clorófita.

O pequeno tamanho dos lobos e os cílios bulbados marginais diferenciam facilmente as espécies deste gênero de todos os demais. Apenas Relicina (Hale \& Kurokawa) Hale, não encontrado na área de estudo, compartilha a formação de cílios bulbados, mas difere 
de Bulbothrix pela substância cortical ácido úsnico (K-).

Candelaria Massalongo (1852) [Lecanorales, Candelariaceae].

Figura 2

Talos foliosos, corticícolas, adnatos, adpressos; córtex superior amarelo vivo a amarelo, sem máculas, medula branca, córtex inferior de cor creme; cílios ausentes; rizinas simples, creme a amareladas, em parte ramificadas nas pontas; apotécios com excípulo talino, adnatos, disco amarelado, himênio com paráfises simples, ascos clavados, ascósporos não encontrados (segundo Brodo et al. 2001, de 20 a 50 por asco, elipsóides, incolores, simples); fotobionte: clorófita.

Os espécimes são facilmente reconhecíveis em campo pelos pequenos talos foliosos aglomerados, de lacínias muito estreitas e de cor amarelada muito forte (calicina e ácido pulvínico).

Canoparmelia Elix \& Hale (1986) [Lecanorales, Parmeliaceae].

Figura 3

Talos foliosos, corticícolas, adnatos, adpressos, córtex superior cinza esverdeado, com máculas puntiformes, lineares ou reticulares, medula branca, córtex inferior negro, com margens marrons; cílios ausentes; rizinas geralmente simples, às vezes parcialmente pouco ramificadas, negras; apotécios com excípulo talino, com pedicelos curtos, disco marrom, himênio com paráfises simples, ascos clavados, contendo oito ascósporos por asco; ascósporos simples, elipsóides, hialinos; fotobionte: clorófita.

Os talos deste gênero são bem adnatos ao substrato, têm lobos pequenos arredondados e geralmente apresentam máculas distintas, sendo sempre eciliados. Espécies deste gênero são comumente encontradas em áreas urbanas [e.g., Canoparmelia texana (Tuck.) Elix \& Hale], devido à capacidade de tolerar melhor as condições destes ambientes e a ação de poluentes, do que espécies de outros gêneros, sendo consideradas potenciais bioindicadoras (Saiki et al. 2007).

\section{Cladonia P. Browne (1756) [Lecanorales,} Cladoniaceae].

Figura 4

Talos dimórficos, terrícolas ou corticícolas, talos primários esquamulosos, adnatos, pouco adpressos, córtex superior cinza esverdeado, medula branca, córtex inferior ausente; talos secundários fruticosos, podécios simples a ramificados, córtex cinza esverdeado, ao menos em parte corticados, ocos, eretos, medula branca a pigmentada salmão; apotécios surgem nos ápices dos podécios, sem excípulo talino, disco marrom ou avermelhado, himênio com paráfises simples a pouco ramificadas, ascos clavados; ascósporos não encontrados (segundo Swinscow \& Krog 1988 e Ahti 2000, são oito ascósporos por asco, simples, elipsóides e hialinos); fotobionte: clorófita.

As espécies deste gênero caracterizam-se por apresentar um talo dimórfico (também chamado de cladoniforme, neste caso) com a parte basal primária formada por pequenas esquâmulas (que podem ser perenes ou efêmeras, se desfazendo conforme o talo se desenvolve), e por uma parte secundária fruticosa, formada por podécios, ocos e eretos.

Coccocarpia Persoon (1827) [Peltigerales, Coccocarpiaceae].

Figura 5

Talos foliosos, corticícolas, adnatos, adpressos a muito adpressos; córtex superior cinza-chumbo a cinza escuro com cristas concêntricas e estrias corticais longitudinais (paraplectenquimático), máculas ausentes, medula branca, córtex inferior creme, esbranquiçado ou escuro; ć́lios ausentes; tomento cinza esverdeado escuro a negro, às vezes com as pontas das hifas claras, podendo ou não estender-se até as margens; apotécios sem excípulo talino, adnatos a sésseis, disco negro, laranja ou marrom, himênio com paráfises simples a ocasionalmente anastomosadas, ascos clavados, contendo oito ascósporos por asco; ascósporos simples ou às vezes com pseudosepto transversal, elipsóides a globosos, hialinos; fotobionte: cianobactéria.

Este gênero caracteriza-se pela coloração cinza chumbo a cinza escuro (devido às cianobactérias), por apresentar estrias radiais visíveis com lupa (córtex paraplectenquimático, com hifas dispostas longitudinalmente), linhas circulares concêntricas geralmente visíveis a olho nu, formação de tomento, e apotécios comumente convexos.

\section{Dirinaria (Tuckerman) Clements}

[Teloschistales, Physciaceae]. Figura 6

Talos foliosos, corticícolas, adnatos, muito adpressos, córtex superior cinza claro, lacínias paralelas plicadas 
e sublineares, comumente confluentes, máculas ausentes, córtex inferior negro; cílios ausentes; sem rizinas; medula branca; apotécios com excípulo talino, adnatos, disco negro, himênio com paráfises simples, ascos clavados, contendo oito ascósporos por asco; ascósporos septados com duas células, de paredes espessas, elipsóides, marrons; fotobionte: clorófita.

Dirinaria difere de Physcia e de Pyxine por não possuir rizinas e pelas lacínias plicadas e lateralmente fundidas. Difere ainda de Physcia por apresentar hipotécio (parte basal do himênio) marrom escuro, enquanto que o desta é claro, e pelo epitécio (parte superior do himênio) que não apresenta reações de coloração, enquanto que o de Pyxine reage $\mathrm{K}+$ púrpura.

Heterodermia Trevisan (1868) [Teloschistales, Physciaceae].

Figuras 7-8

Talos foliosos, corticícolas ou muscícolas, pouco adnatos a adnatos, pouco adpressos a adpressos, córtex superior cinza esverdeado, cinza claro a esbranquiçado, máculas ausentes, córtex inferior, quando presente, de coloração variada; medula branca ou com pigmentação muito variada (e.g. vermelha, amarela, roxa, etc.), cílios sempre presentes, simples, ramificados ou esquarosos; quando com córtex inferior, pode haver rizinas simples a ramificadas, esparsas; apotécios com excípulo talino, adnatos a pedicelados, disco marrom escuro, himênio com paráfises ramificadas a anastomosadas, ascos clavados, ascósporos septados com duas células, elipsóides, marrons; fotobionte: clorófita.

Este gênero apresenta bastante variação morfológica, desde talos com finas lacínias, às vezes eretas com aspecto que se assemelha ao de um talo fruticoso, a talos com lobos mais arredondados e pequenos, com cílios que podem surgir até sobre o córtex superior. A característica principal das espécies desse gênero é o arranjo prosoplectenquimático do córtex superior (disposição longitudinal das hifas), a presença e forma dos cílios e o tipo de ascósporos. A ausência de córtex inferior em muitas das espécies é também uma característica bem típica.

Hypotrachyna (Vainio) Hale (1974) [Lecanorales, Parmeliaceae].

Figura 9

Talos foliosos, corticícolas, adnatos, adpressos, córtex superior cinza esverdeado, máculas não encontradas (são na maioria das vezes inconspícuas quando presentes, segundo Jungbluth 2006); medula branca, córtex inferior negro no centro e de margens marrons a cremes; cílios sempre ausentes; rizinas dicotomicamente ramificadas, normalmente abundantes, negras, surgindo até junto as margens; apotécios com excípulo talino, com pedicelos curtos, himênio com paráfises simples, ascos clavados, contendo oito ascósporos por asco; ascósporos simples, elipsóides, hialinos; fotobionte: clorófita.

Talos de Hypotrachyna possuem morfologia similar aos dos gêneros Bulbothrix e Parmelinopsis, porém se distinguem destes pela presença de rizinas dicotômicas combinadas à total ausência de cílios nas margens. Talos de Canoparmelia também não formam cílios, mas têm rizinas simples, e lobos mais arredondados.

Leptogium (Acharius) Gray (1821) [Peltigerales, Collemataceae].

Figura 10

Talos foliosos, corticícolas, adnatos, pouco adpressos, homômeros (sem distinção entre medula e camada de fotobiontes), córtex superior negro fosco a cinza chumbo, máculas ausentes, medula verde acinzentada escura, córtex inferior negro a cinza esverdeado escuro com uma a três camadas de células; cílios e rizinas ausentes; apotécios com excípulo talino, pedunculados, adnatos ou sésseis, disco vermelho amarronzado, himênio com paráfises simples, ascos clavados, contendo oito ascósporos por asco, ascósporos muriformes fusiformes, acinzentados a incolores; fotobionte: cianobactéria.

Este gênero caracteriza-se pelos talos homômeros muito delgados, de coloração escura cinza chumbo, cinza-esverdeado ou negro quando secos, devido à presença de cianobactérias (tendo aspecto de papel queimado), e que adquirem uma aparência gelatinosa quando úmidos, devido a grande capacidade de absorção de água, além de seus esporos muriformes fusiformes.

Myelochroa (Asahina) Elix \& Hale (1987) [Lecanorales, Parmeliceae].

Figura 11

Talos foliosos, corticícolas, adnatos e adpressos, córtex superior cinza esverdeado, máculas não encontradas (podem ser fracas e puntiformes em algumas espécies, segundo Jungbluth 2006), medula amarelada, córtex inferior negro, com margens 


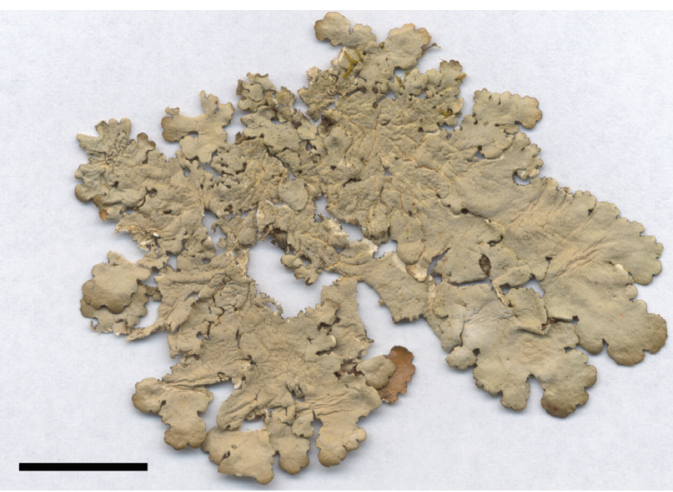

1
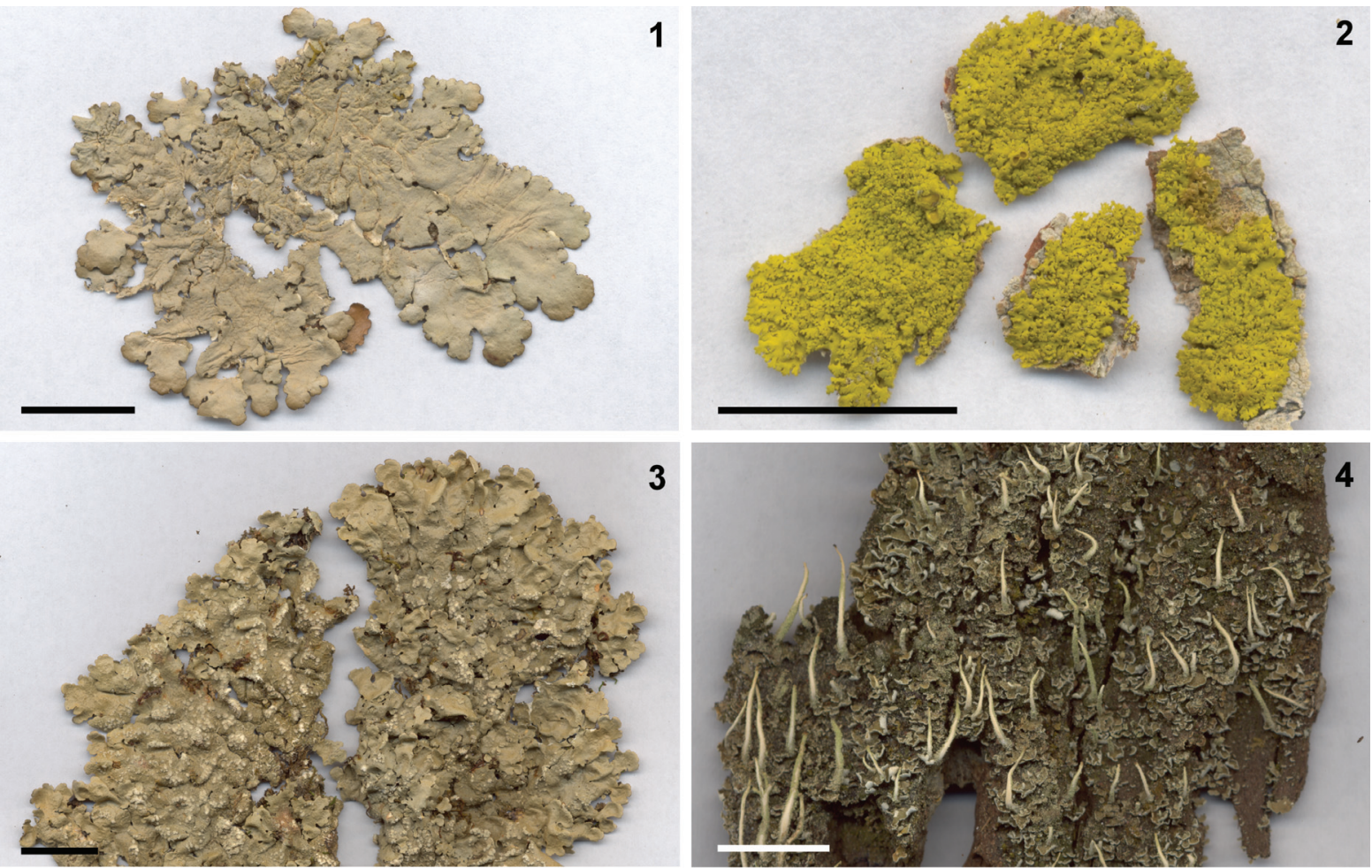

3
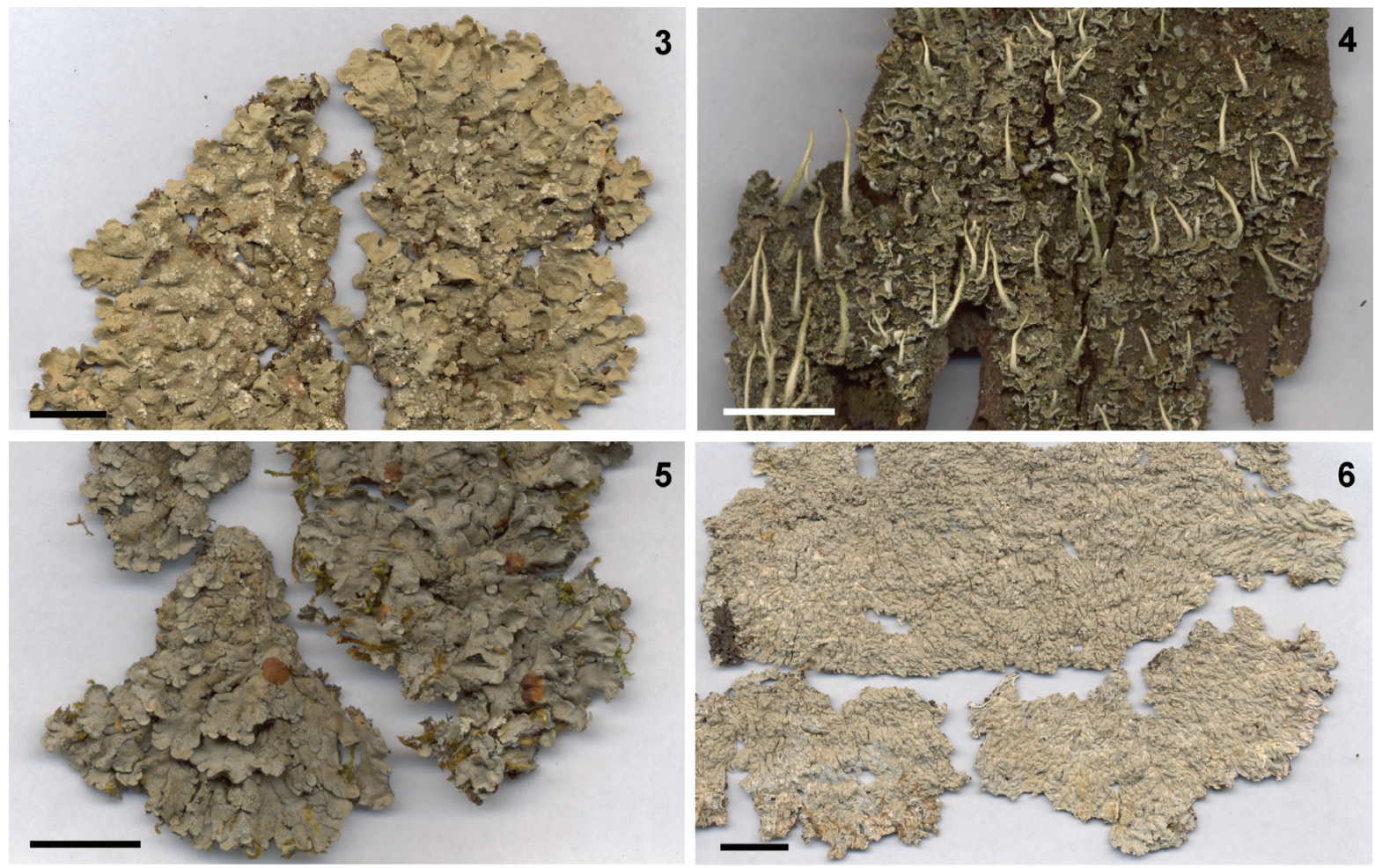

5
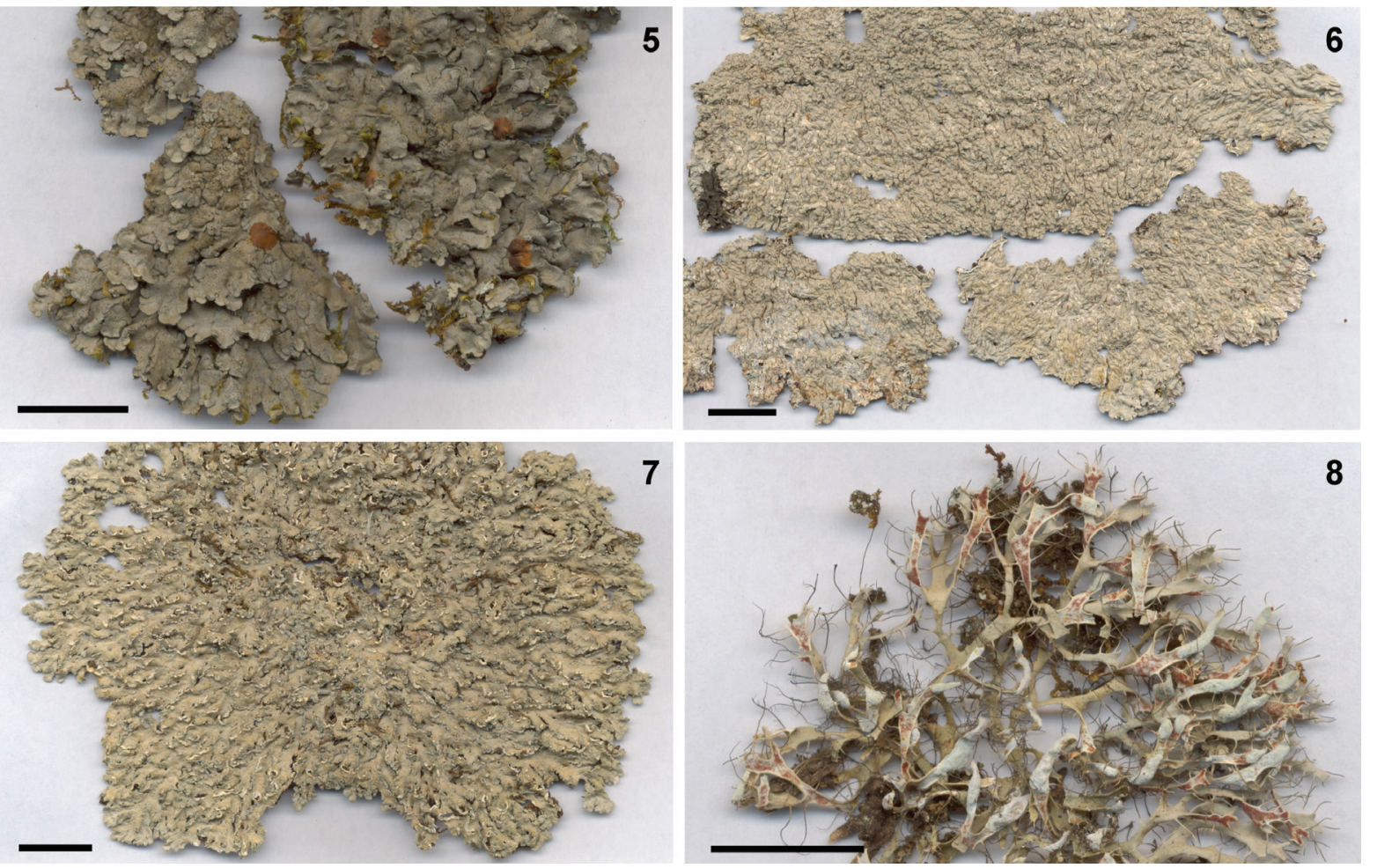

Figuras 1-8. Espécimes de gêneros de fungos liquenizados do campus da Universidade Federal de São Carlos. 1. Bulbothrix sp. (Benatti 2135). 2. Candelaria sp. (Batista 88). 3. Canoparmelia sp. (Benatti 2088). 4. Cladonia sp. (Batista 8). 5. Coccocarpia sp. (Benatti 2180). 6. Dirinaria sp. (Batista 28). 7. Heterodermia sp. (Batista 39). 8. Heterodermia sp. (Batista 100, espécie sem córtex inferior). Barras de escala $=1 \mathrm{~cm}$.

Figures 1-8. Lichenized fungi genera specimens from the campus of the Universidade Federal de São Carlos. 1. Bulbothrix sp. (Benatti 2135). 2. Candelaria sp. (Batista 88). 3. Canoparmelia sp. (Benatti 2088). 4. Cladonia sp. (Batista 8). 5. Coccocarpia sp. (Benatti 2180). 6. Dirinaria sp. (Batista 28). 7. Heterodermia sp. (Batista 39). 8. Heterodermia sp. (Batista 100, species without lower cortex). Scale bars $=1 \mathrm{~cm}$. 
marrons; cílios simples a furcados, curtos, axilares, poucos, enegrecidos ou às vezes marrons quando jovens; rizinas simples, negras, às vezes marrons, ou com ápice esbranquiçado quando próximas às margens; apotécios com excípulo talino, adnatos ou com pedicelos curtos, himênio geralmente com paráfises simples, às vezes em parte pouco ramificadas, ascos clavados, contendo oito ascósporos por asco; ascósporos simples, elipsóides, hialinos; fotobionte: clorófita.

Este gênero caracteriza-se por apresentar talos com lobos subarredondados a arredondados, cílios pouco freqüentes a escassos axilares e medula sempre amarelada. Os espécimes em geral apresentam medula de cor amarelo vivo (devido à presença de ácido secalônico A).

Parmelinella Elix \& Hale (1987) [Lecanorales, Parmeliaceae].

Figura 12

Talos foliosos, corticícolas, adnatos, adpressos, córtex superior cinza esverdeado, máculas ausentes, medula branca, córtex inferior negro a marrom; medula branca; cílios simples, restritos às axilas, negros; rizinas simples, negras; apotécios com excípulo talino, subpedicelados a adnatos, himênio com paráfises simples, ascos clavados, contendo oito ascósporos por asco, ascósporos simples, elipsóides, hialinos; fotobionte: clorófita.

Parmelinella possui morfologia um tanto similar a Parmelinopsis, porém difere deste gênero por apresentar lobos mais arredondados, cílios simples restritos às axilas dos lobos, e sempre apresentam ácido salazínico na medula, que não ocorre em espécies de Parmelinopsis.

\section{Parmelinopsis Elix \& Hale (1987) [Lecanorales,} Parmeliaceae].

\section{Figura 13}

Talos foliosos, corticícolas, adnatos, adpressos a muito adpressos, córtex superior cinza esverdeado a verde, máculas não encontradas (podem ser inconspícuas, puntiformes a reticulares segundo Jungbluth 2006), medula branca ou raramente amarelada, córtex inferior negro no centro com margens marrons; cílios simples ou raramente ramificados, freqüentes a abundantes, marginais, curtos, negros; rizinas simples ou irregularmente ramificadas, negras, escassas a abundantes, até as margens; apotécios com excípulo talino, subpedice- lados, himênio com paráfises simples, ascos clavados, contendo oito ascósporos por asco; ascósporos simples, elipsóides, hialinos; fotobionte: clorófita.

Este gênero se caracteriza pelos cílios marginais abundantes, lacínias alongadas, e pelas rizinas simples a irregularmente ramificadas. Talos de Canoparmelia e Hypotrachyna podem apresentar morfologia similar, porém nunca formam cílios, enquanto que talos Parmelinella formam cílios restritos somente às axilas dos lobos. Canoparmelia tem ainda lobos mais arredondados normalmente maculados, Hypotrachyna tem rizinas evidentemente dicotômicas, e Parmelinella sempre apresenta ácido salazínico medular.

Parmotrema Massalongo (1860) [Lecanorales, Parmeliaceae].

Figuras 14-16

Talos foliosos, corticícolas, adnatos, adpressos a pouco adpressos, córtex superior cinza esverdeado, máculas ausentes a presentes, em alguns grupos podendo ser reticuladas originando quebras ou então puntiformes efiguradas, medula branca, as vezes pigmentada amarelada ou alaranjada; córtex inferior negro no centro, de margens marrons às vezes tornando-se brancas, cremes ou variegadas; cílios presentes ou ausentes, marginais, simples a ramificados, enegrecidos; rizinas simples ou em parte pouco irregularmente ramificadas, em alguns grupos esquarrosas ou dimórficas com um misto de longas e grossas e pequenas e finas, negras, normalmente ausentes nas margens, exceto quando nos grupos de córtex com máculas efiguradas ou reticulares; apotécios com excípulo talino, pedicelados a subpedicelados, perfurados ou imperfurados, himênio com paráfises simples, ascos clavados, contendo oito ascósporos por asco, ascósporos simples, elipsóides, hialinos; fotobionte: clorófita.

Parmotrema em seu senso atual (Blanco et al. 2005) engloba as espécies de outros três gêneros: Canomaculina, Rimelia e Concamerella (este último ainda conhecido somente para o sul do Brasil e Uruguai). As características das máculas e das rizinas eram originalmente usadas para diferenciar espécies de Canomaculina e de Rimelia das de Parmotrema. As espécies anteriormente referidas como Canomaculina apresentam máculas puntiformes efiguradas no córtex superior e dimorfismo de rizinas, enquanto que as de Rimelia apresentam máculas reticulares que originam quebras (rimosidades) e rizinas comumente esquarrosas. Foram encontrados 

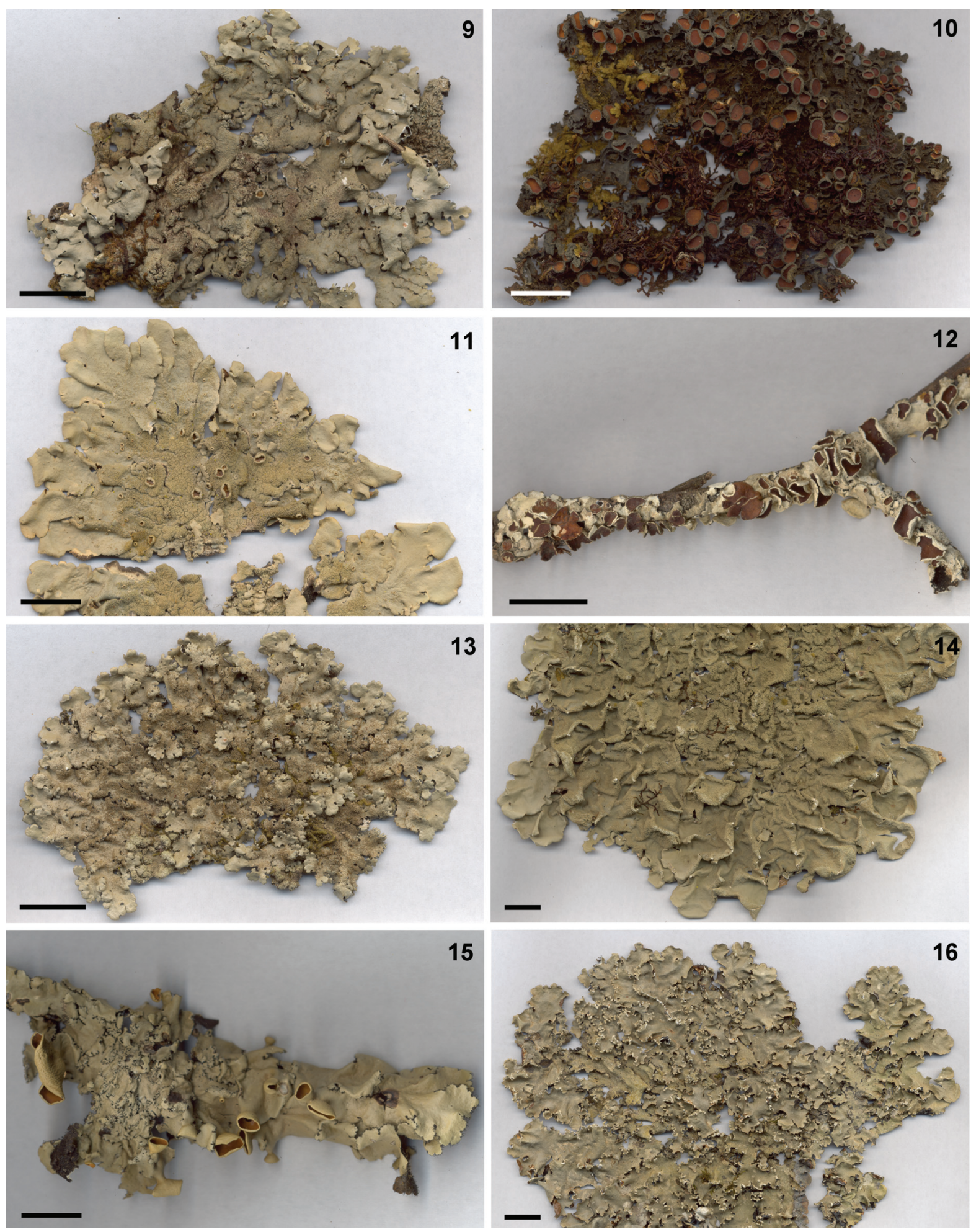

Figuras 9-16. Espécimes de gêneros de fungos liquenizados do campus da Universidade Federal de São Carlos. 9. Hypotrachyna sp. (Benatti 2186). 10. Leptogium sp. (Benatti 2129). 11. Myelochroa sp. (Benatti 2091). 12. Parmelinella sp. (Batista 66A). 13. Parmelinopsis sp. (Benatti 2139). 14. Parmotrema sp. (Batista 50). 15. Parmotrema sp. (ex Canomaculina, Benatti 2174). 16. Parmotrema sp. (ex Rimelia, Batista 93). Barras de escala $=1 \mathrm{~cm}$.

Figures 9-16. Lichenized fungi genera specimens from the campus of the Universidade Federal de São Carlos. 9. Hypotrachyna sp. (Benatti 2186). 10. Leptogium sp. (Benatti 2129). 11. Myelochroa sp. (Benatti 2091). 12. Parmelinella sp. (Batista 66A). 13. Parmelinopsis sp. (Benatti 2139). 14. Parmotrema sp. (Batista 50). 15. Parmotrema sp. (ex Canomaculina, Benatti 2174). 16. Parmotrema sp. (ex Rimelia, Batista 93). Scale bars $=1 \mathrm{~cm}$. 
espécimes que se enquadram nas características que anteriormente separavam os três gêneros na área de estudo.

Physcia (Schreber) Michaux (1803) [Teloschistales, Physciaceae].

Figura 17

Talos foliosos, corticícolas, adnatos, adpressos, córtex superior cinza esverdeado, cinza claro ou cinza azulado, máculas ausentes a presentes, puntiformes a lineares, laminais, medula branca ou creme, córtex inferior creme a marrom no centro e de margens acinzentadas a cremes; cílios ausentes; rizinas simples a pouco irregularmente ramificadas, cremes, marrons ou cinzas, geralmente concoloridas ao córtex; apotécios com excípulo talino, adnatos, subpedicelados a sésseis, disco negro às vezes pruinoso, himênio com paráfises ramificadas, ascos clavados, contendo oito ascósporos por asco; ascósporos biloculares, elipsóides, amarronzados; fotobionte: clorófita.

Physcia pode ser diferenciado de Pyxine pela reação $\mathrm{K}+$ amarelo no córtex, apotécios com hipotécios claros ao invés de marrons, e excipulo talino permanente. Pode ser diferenciado de Heterodermia pelo arranjo paraplectenquimático das hifas do córtex superior, ao invés do arranjo prosoplectênquimático, por não apresentar estrias radiais no córtex, e por ter sempre córtex inferior.

Pseudocyphellaria Vainio (1890) [Peltigerales, Lobariaceae].

Figura 18

Talos foliosos, corticícolas, pouco adnatos, pouco adpressos, córtex superior verde escuro a marrom, máculas ausentes, medula amarela (ou branca, não encontrada), córtex inferior com coloração salmão ou de tons variados de marrom ou creme, com pseudocifelas; cílios ausentes; tomento marrom claro (ao negro, não encontrado), com margens em parte nuas; apotécios com excípulo talino, subpedicelados, himênio com paráfises simples, ascos clavados, contendo oito ascósporos por asco; ascósporos transversalmente septados, com 2 a 4 células, fusiformes, hialinos a marrons; fotobiontes: clorófita ou cianobactéria.

Este gênero é caracterizado pela presença de pseudocifelas no córtex inferior (por onde se vê a medula extravasando), formação de tomento e esporos bifusiformes transversalmente septados. Espécies deste gênero podem fazer simbiose com clorófitas ou com cianobactérias, ou ainda mais raramente (Brodo et al. 2001) com ambos, formando associações quimeróides ou quimeras (talos com lobos alternando fotobiontes) ou cefalódios (estruturas cerebróides formadas por aglomerações de cianobactérias em talos contendo clorófitas).

Punctelia Krog (1982) [Lecanorales, Parmeliaceae]. Figura 19

Talos foliosos, corticícolas, adnatos a muito adnatos, adpressos a muito adpressos, córtex superior verde a cinza esverdeado com pseudocifelas, máculas às vezes presentes, medula branca, córtex inferior marrom escuro a marrom claro no centro, margens marrom claras, cremes ou acinzentadas; cílios ausentes; rizinas simples a irregularmente ramificadas, marrom claras a cremes, rizinado até as margens; apotécios não encontrados (segundo Swinscow \& Krog 1988 e Canêz 2005, têm excípulo talino, sendo adnatos a pedunculados, perfurados ou não; himênio com paráfises simples, ascos clavados, contendo oito ascósporos por asco; ascósporos simples, elipsóides a ovais, hialinos); fotobionte: clorófita.

Este gênero pode ser facilmente reconhecido pela presença de pseudocifelas (um tipo de poro) no córtex superior, e pelos talos verdes a cinza esverdeados sempre eciliados.

Pyxine Fries (1825) [Teloschistales, Physciaceae]. Figura 20

Talos foliosos, corticícolas, adnatos a muito adnatos, adpressos a muito adpressos, córtex superior cinza esverdeado, máculas presentes, lineares, laminais; medula branca a amarelada, córtex inferior negro no centro de margens verdes escuras a cinzas escuras; cílios ausentes; rizinas simples, ramificadas ou aglutinadas; apotécios sem excípulo talino, ao menos quando amadurecidos, disco negro, himênio com paráfises simples, hipotécio marrom, ascos clavados, contendo oito ascósporos por asco; ascósporos biloculares, elipsóides, marrons com paredes celulares grossas; fotobionte: clorófita.

Este gênero pode ser reconhecido pela característica peculiar de seus apotécios perderem o excípulo talino conforme amadurecem (são lecanorinos apenas quando muito jovens). Difere de Physcia por características dos córtices inferior e superior e do himênio dos apotécios. Outras diferenças para com Physcia e Heterodermia 
podem ser encontradas nos respectivos comentários.

Ramalina Acharius (1810) [Lecanorales, Ramalinaceae].

Figura 21

Talos fruticosos, corticícolas, apressório basal marrom, eretos ou pedunculados, córtex às vezes parcialmente descontínuo, cinza esverdeado a amarronzado, os apressórios basais mais escuros ou esverdeados, máculas ausentes ou presentes, lineares; medula branca ou amarelada, às vezes aracnóide (frouxa); cílios ausentes; apotécios com excípulo talino, pedicelados, apicais e laterais, disco salmão, recoberto com pruína branca ou verde clara, himênio com paráfises anastomosadas, ascos clavados, contendo oito ascósporos por asco; ascósporos biloculares, elipsóides, hialinos; fotobionte: clorófita.

Este gênero é caracterizado pelo talo fruticoso com ramificações achatadas, pelo córtex que pode ser ocasionalmente perfurado, e pela medula que varia de densa a aracnóide. Espécies deste gênero não apresentam eixos condróides centrais tais como Usnea, cujas ramificações são cilíndricas. Teloschistes difere pelas ramificações cilíndricas e pela presença de uma substância de cor amarela ou alaranjada $\mathrm{K}+$ púrpura, normalmente presente em todo o talo, ou ao menos nos apotécios.

Sticta (Schreber) Acharius (1803) [Peltigerales, Lobariaceae].

Figura 22

Talos foliosos, corticícolas, pouco adnatos, pouco adpressos, córtex superior marrom esverdeado; cílios ausentes; máculas ausentes, medula branca ou creme, córtex inferior marrom escuro no centro de margens marrons claras, com cifelas, tomento marrom, margem nua; apotécios com excípulo talino, subpedicelados a adnatos, himênio com paráfises simples, ascos clavados, contendo oito ascósporos por asco; ascósporos transversalmente septados, com 2-4 (e 5) células, fusiformes, hialinos a marrons; fotobionte: cianobactéria (segundo Galloway 1985 e 2007, também podem ser clorófitas, estas não encontradas).

Talos de Sticta são bastante semelhantes na morfologia aos de outros dois gêneros de Lobariaceae, Pseudochyphellaria (que formam pseudocifelas) e Lobaria (que não forma nenhum tipo de poro ou abertura), sendo que espécimes deste último não foram encontrados na área de estudo.

Teloschistes Norman (1853) [Teloschistales, Teloschistaceae].

Figura 23

Talos fruticosos, corticícolas, com apressório basal, córtex amarelo a alaranjado, com ramificações dicotômicas regulares ou irregulares, cilíndricas, máculas ausentes; medula creme; cílios ausentes ou presentes; apotécios com excípulo talino, no ápice das ramificações, himênio com paráfises simples, ascos clavados, contendo oito ascósporos por asco; ascósporos polariloculares, elipsóides, hialinos; fotobionte: clorófita.

Talos deste gênero são caracterizados principalmente por sua coloração geralmente amarelada a alaranjada (em algumas espécies esverdeadas, a coloração mais amarela é restrita aos apotécios), pelos talos arbustivos, pelos ascósporos polariloculares e pela reação $\mathrm{K}+$ púrpura cortical devido às substâncias amareladas que dão a cor aos talos.

Usnea Dillenius ex Adanson (1763) [Lecanorales, Parmeliaceae].

Figura 24

Talos fruticosos, corticícolas, com apressório basal, pendulosos ou eretos, de ramificações irregulares, cilíndricas, córtex cinza esverdeado a marrom esverdeado, máculas ausentes; medula branca ou pigmentada de amarelo, salmão, róseo ou avermelhado, com cordão axial condróide branco (ou pigmentado, não encontrado), cílios típicos ausentes, mas fibrilas (algo como cílios revestidos por córtex) podem estar presentes por todo talo; apotécios com excípulo talino, apicais, disco salmão, marrom ou amarelado, podendo ou não apresentar pruína, himênio com paráfises simples a pouco ramificadas, ascos clavados, contendo oito ascósporos por asco; ascósporos simples, elipsóides, hialinos; fotobionte: clorófita.

Talos dos gêneros fruticosos Teloschistes e Ramalina diferem dos de Usnea principalmente por não possuírem um eixo central condróide. O primeiro tem ainda ascósporos e química cortical diferentes, e o segundo tem ramificações achatadas ao invés de cilíndricas. 



Figuras 17-24. Espécimes de gêneros de fungos liquenizados do campus da Universidade Federal de São Carlos. 17. Physcia sp. (Benatti 2098). 18. Pseudocyphellaria sp. (Benatti 2140). 19. Punctelia sp. (Benatti 2086). 20. Pyxine sp. (Batista 25). 21. Ramalina sp. (Benatti 2104). 22. Sticta sp. (Batista 141). 23. Teloschistes sp. (Benatti 2157). 24. Usnea sp. (Benatti 2148). Barras de escala $=1 \mathrm{~cm}$.

Figures 17-24. Lichenized fungi genera specimens from the campus of the Universidade Federal de São Carlos. 17. Physcia sp. (Benatti 2098). 18. Pseudocyphellaria sp. (Benatti 2140). 19. Punctelia sp. (Benatti 2086). 20. Pyxine sp. (Batista 25). 21. Ramalina sp. (Benatti 2104). 22. Sticta sp. (Batista 141). 23. Teloschistes sp. (Benatti 2157). 24. Usnea sp. (Benatti 2148). Scale bars $=1 \mathrm{~cm}$. 


\section{Literatura citada}

Ahti, T. 2000. Cladoniaceae. Flora Neotropica. Monograph 78: 1-362.

Aptroot, A. 1987. Pyxinaceae (Lichens). Flora of the Guianas, Series E (Fungi and Lichens) 1: 1-59.

Benatti, M.N. 2005. Os gêneros Canomaculina, Parmotrema e Rimelia (Parmeliaceae, Ascomycetes) no litoral centro-sul do Estado de São Paulo. Dissertação de Mestrado, Instituto de Botânica, São Paulo.

Benatti, M.N. \& Marcelli, M.P. 2007. Gêneros de fungos liquenizados dos manguezais do sul-sudeste do Brasil, com enfoque no manguezal do Rio Itanhaém, São Paulo. Acta Botanica Brasílica 21: 863-878.

Blanco, O., Crespo, A., Divakar, P.K., Elix, J.A. \& Lumbsch, H.T. 2005. Molecular phylogeny of parmotremoid lichens (Ascomycota, Parmeliaceae). Mycologia 97: 150-159.

Brodo, I.M., Duran Sharnoff, S. \& Sharnoff, S. 2001. Lichens of North America. Yale University Press, New Haven.

Canêz, L.S. 2005. A família Parmeliaceae na Localidade de Fazenda da Estrela, município de Vacaria, Rio Grande do Sul, Brasil. Dissertação de Mestrado, Instituto de Botânica, São Paulo.

Canêz, L.S. \& Marcelli, M.P. 2009. Gêneros de Parmeliaceae (Ascomycetes liquenizados) na localidade de Fazenda da Estrela, Vacaria, Rio Grande do Sul, Brasil. Caderno de Pesquisa. Série Biologia (UNISC) 18: 41-95.

Coutinho, L.M. 1978. O Conceito de Cerrado. Revista Brasileira de Botânica 1: 17-23.

Fink, B. 1905. How to collect and study lichens. The Bryologist 8: 22-27.

Fleig, M. \& Medeiros Filho, J.W. 1990. Gêneros dos liquens saxícolas, corticícolas e terrícolas do Morro Santana, Porto Alegre, RS, Brasil. Acta Botanica Brasilica 4: 73-99.

Galloway, D.J. 1985. Flora of New Zealand Lichens. Government Printer, Wellington.

Galloway, D.J. 2007. Flora of New Zealand Lichens. Revised Second Edition Including Lichen-Forming and Lichenicolous Fungi. v. 1,2. Manaaki Whenua Press, Lincoln.

Hale, M.E. 1979. How to know the lichens. The PicturedKey Nature Series. Wm. C. Brown, Dubuque.
Hale, M.E. 1987. How to know the lichens. 2 ed. WCB/ McGraw-Hill, Boston.

Jungbluth, P. 2006. A família Parmeliaceae (fungos liquenizados) em cerrados do Estado de São Paulo, Brasil. Dissertação de Mestrado, Instituto de Botânica, São Paulo.

Kirk, P.M., Cannon, P.F., Minter, D.W. \& Stalpers, J.A. 2008. Dicitinary of Fungi, 10 ed. CAB International, Wallinford.

Marcelli, M.P. 1996. Biodiversity assessment in lichenized fungi: the necessary naive roll makers. In: C.E.M Bicudo \& N.A. Menezes (eds.). Biodiversity in Brazil: a first approach. Conselho Nacional de Desenvolvimento Científico e Tecnológico, São Paulo, pp. 93-107.

Paese, A. 1997. Caracterização e análise ambiental do campus da Universidade Federal de São Carlos (UFSCar), São Carlos, SP. Dissertação de Mestrado, Universidade Federal de São Carlos, São Carlos.

Purvis, W. 2000. Lichens. Natural History Museum / Smithsonian Institution, London, Washington D.C.

Ribeiro, C.H. 1998. A família Parmeliaceae (Ascomycota liquenizados) em regiões montanhosas dos estados de Minas Gerais, Rio de Janeiro e São Paulo. Dissertação de Mestrado, Universidade de São Paulo, São Paulo.

Saiki, M., Fuga, A., Alves, E.R., Vasconcellos, M.B.A. \& Marcelli, M.P. 2007. Biomonitoring of the atmospheric pollution using lichens in the metropolitan area of São Paulo city, Brazil. Journal of Radioanalytical and Nuclear Chemistry 271:213-219.

Spielmann, A.A. 2005. A família Parmeliaceae (fungos liquenizados) nos barrancos e peraus da encosta da Serra Geral, Vale do Rio Pardo, Rio Grande do Sul, Brasil. Dissertação de Mestrado, Instituto de Botânica, São Paulo.

Spielmann, A.A. \& Marcelli, M.P. 2008. Parmeliaceae (Ascomycota liquenizados) nos barrancos e peraus da encosta da Serra Geral, Vale do Rio Pardo, Rio Grande do Sul, Brasil. I. Introdução e chave para os gêneros. Iheringia, Série Botânica 63: 159-169.

Swinscow, T.D.V. \& Krog, H. 1988. Macrolichens of East Africa, v. 1. British Museum, London. 